O pronera e educação de jovens e adultos nos assentamentos e acampamentos rurais do Estado do Rio de Janeiro Elisangela das Dores de Carvalho, Luana de Carvalho Aguiar, Thiago Lucas Alves da Silva

\title{
O PRONERA E EDUCAÇÃO DE JOVENS E ADULTOS NOS ASSENTAMENTOS E ACAMPAMENTOS RURAIS DO ESTADO DO RIO DE JANEIRO
}

\section{PRONERA and education of youths and adults in rural settlements and camps of Rio de Janeiro}

Elisangela das Dores de Carvalho ${ }^{I}$ Pós-Graduação (especialização) pelo PRONERA em Trabalho, Educação e Movimentos Sociais em parceria com a EPSJV/FIOCRUZ e o MST.

Luana de Carvalho Aguiar ${ }^{2}$ Possui Pós-Graduação (especialização) pelo PRONERA em Trabalho, Educação e Movimentos Sociais em parceria com a EPSJV/FIOCRUZ e o MST.

Thiago Lucas Alves da Silva ${ }^{3}$ Professor de Geografia. Mestre em Desenvolvimento, Sociedade e Agricultura pela UFRRJ/CPDA.

Artigo recebido em 09/07/2013 e aceito para publicação em 29/11/2013

DOI: 10.12957/tamoios.2013.7364

RESUMO O presente artigo tem como objetivo apresentar os avanços e desafios do PRONERA, sobretudo em seus cursos de Educação de Jovens e Adultos (EJA) realizados em áreas de acampamentos e assentamentos de trabalhadores rurais no estado do Rio de Janeiro. Neste sentido, faremos uma breve exposição acerca da origem do PRONERA e da Educação do Campo e a repercussão desse debate nos assentamentos e acampamentos rurais, especialmente, aqueles que foram contemplados com projetos do PRONERA.

Palavras-chave: PRONERA; Educação do Campo; Reforma Agrária.

ABSTRACT The article presented here aims to present and reflect on the progress and challenges of PRONERA, especially in his courses Education for Youth and Adults (EJA) on areas of camps and settlements of rural workers in the state of Rio de Janeiro. In this sense we will make a brief statement about the origin of PRONERA and Field Education and the repercussions of this debate in rural settlements and camps, especially those who were awarded projects PRONERA.

Keywords: PRONERA; Field Education; Agrarian Reform. 


\section{1- UM BREVE HISTÓRICO DO PROGRAMA NACIONAL DE EDUCAÇÃO NA REFORMA AGRÁRIA (PRONERA)}

O Programa Nacional de Educação na Reforma Agrária - PRONERA surgiu em 1998 como fruto da luta dos movimentos sociais do campo pelo direito à educação pública de qualidade e pelo acesso aos povos do campo à própria educação, direito este que lhes foi historicamente negado.

Nesse sentido, os movimentos sociais do campo, em especial o Movimentos dos Trabalhadores Rurais Sem Terra - MST, discutem desde sua constituição a problemática da educação, entendendo que era preciso pensar uma nova proposta de educação que desse conta das especificidades do campo.

Sendo assim, o Programa Nacional de Educação na Reforma Agrária foi concebido no Primeiro Encontro Nacional das Educadoras e Educadores da Reforma Agrária (ENERA), no período de 27 a 31 de julho de 1997, em Luziânia - GO. Nesse encontro estiveram presentes, entre outros, movimentos sociais e entidades como a Conferência Nacional dos Bispos do Brasil - CNBB, Fundo das Nações Unidas para a Infância - UNICEF, Organização das Nações Unidas para a Educação, a Ciência e a Cultura - UNESCO e a Universidade de Brasília - UNB, com o intuito de ampliar as discussões sobre a educação no meio rural.

A Educação do Campo então surgiu para se contrapor ao modelo de educação rural que ainda hoje persiste no campo brasileiro, controlado pelo agronegócio. Ela parte das experiências dos movimentos sociais que têm como principal fundamento a relação da teoria com a prática, ou seja, da luta cotidiana pela transformação da sociedade e que, para isso, exige que esta educação seja pensada a partir destes sujeitos e de onde eles se inserem socialmente.

Por isso, a educação do campo combina luta pela educação com luta pela terra, pela Reforma Agrária, pelo direito ao trabalho, à cultura, à soberania alimentar, ao território (Caldart 2012).

Apesar de ser uma nomenclatura recente, seu conceito expressa a luta dos trabalhadores do campo há décadas pela educação, na garantia de políticas públicas voltadas aos interesses da classe trabalhadora e que vem representar uma nova forma de pensar a educação, diferentemente das práticas pedagógicas adotadas na realidade da educação rural.

Foi nesse contexto de lutas pela Educação do Campo e por políticas públicas que surgiu o PRONERA em 16 de abril de 1998, por meio da portaria $\mathrm{N}^{\circ} 10 / 1998$, publicada pelo então Ministério Extraordinário da Política Fundiária e que foi ratificado como política pública pelo Decreto $\mathrm{N}^{\circ} 7.352$ de 4 de novembro de 2010.

De acordo com o texto "Balanço Político e Linhas de Ação do PRONERA Rumo aos 10 anos":

O PRONERA tem como objetivo geral fortalecer a educação nas áreas de Reforma Agrária estimulando, propondo, criando, desenvolvendo e coordenando projetos educacionais, utilizando metodologias voltadas para a especificidade do campo, tendo em vista contribuir para a promoção do desenvolvimento sustentável (SANTOS 2008:97).

O programa está vinculado ao Instituto Nacional de Colonização e Reforma Agrária (INCRA) -, atuando em parceria com os movimentos sociais, organizando convênios com instituições públicas, como universidades, Institutos Federais de Educação, escolas família- 
$\overline{\text { agrícola, institutos de educação e secretarias municipais e estaduais de educação em cada }}$ estado.

Com o PRONERA surgiu a oportunidade de garantir a alfabetização e escolarização de milhares de trabalhadores do campo que ainda se encontravam marginalizados e excluídos dos códigos de linguagem da sociedade brasileira. No Brasil, consta que 23,2\% de residentes na área rural ainda são analfabetos ${ }^{4}$, em 2000 esse número era de $29,8 \%$.

O PRONERA instituiu possibilidades de ressignificação do conteúdo e da metodologia dos processos de educação formal, por meio dos princípios básicos da participação e da multiplicação. A participação se materializa pelo fato de que a indicação das demandas educacionais é feita pelas comunidades das áreas de Reforma Agrária e suas organizações, que, em conjunto com os demais parceiros, decidirão sobre a elaboração, o acompanhamento e a avaliação dos projetos. Já a multiplicação se realiza porque a educação dos assentados visa à ampliação não só do número de pessoas alfabetizadas e formadas em diferentes níveis de ensino, mas também garantir educadores, profissionais, técnicos, agentes mobilizadores e articuladores de políticas públicas para as áreas de Reforma Agrária. (SANTOS 2012: 633)

Com o passar dos anos, identificando a necessidade de uma continuidade dos estudos destes sujeitos que vivem no campo e com a intenção também de ocupar as instituições públicas de educação que historicamente os trabalhadores pouco acesso tiveram, os movimentos sociais foram pautando principalmente nas universidades a construção de projetos de ensino médio e profissionalizante, graduação e pós-graduação.

Atualmente, o programa desenvolve projetos de EJA, de ensino médioltécnico, graduação e pós-graduação. No entanto, o principal foco de atenção nos primeiros anos de sua existência foi com a Educação de Jovens e Adultos, tendo em vista que os índices de analfabetismos no meio rural do Brasil eram (são) elevados, especialmente nos assentamentos da Reforma Agrária (Kolling, Nery \& Molina 1999), como foi demonstrado pela primeira pesquisa nacional de educação na reforma agrária.

A escolaridade nos assentamentos rurais é baixa e há um alto índice de analfabetismo, chegando em alguns Estados a 70\% e registrando uma média nacional de $45 \%$, ou seja, o percentual de analfabetos nos assentamentos rurais do país é maior que a média do país. Estas altas taxas de analfabetismo no meio rural acontecem devido uma série de fatores, como: dificuldades de acesso às escolas (estradas precárias), necessidade das crianças em ajudar os pais nas tarefas diárias nas propriedades, distâncias das propriedades até as escolas. Os índices de analfabetismo no meio rural brasileiro, permanecendo nos níveis em que se encontram, podem ser um forte obstáculo à viabilização da Reforma Agrária no país. Na maioria dos casos o ensino que é oferecido à população rural é o mesmo que é dado a população urbana, nem sempre sendo o mais adequado a quem mora no campo, visto que o contexto é diferente no que diz respeito a valores e cultura. 
A educação do campo deve ser uma educação que assuma a identidade do meio rural, nos seus mais diversos aspectos. O PRONERA tem concepção no sentido de trabalhar com estas especificidades (INEP/ I PNERA 2004).

Visando combater os altos índices de analfabetismo, o PRONERA se desenvolveu em conjunto com uma proposta de educação do campo emancipatória, interligada a um processo de transformação social do campo brasileiro buscando enfrentar a histórica precarização da educação no meio rural, resultado de uma concepção que vê no campo o local do atraso e nega às populações rurais o direito a uma educação de qualidade (Arroyo 2004).

Neste sentido, o programa em geral busca desenvolver um projeto de educação do campo que reconhece o saber popular, que valoriza o conhecimento dos educandos e leva em consideração as especificidades do campo, como exposto abaixo:

A educação do campo deve ser uma educação que assuma a identidade do meio rural, não só como uma cultura diferenciada, mas como um contexto em que se efetive um projeto de desenvolvimento do campo, ou seja, uma escola do campo comprometida com um projeto político-pedagógico vinculado às causas, aos desafios, aos sonhos, à história e à cultura de quem vive e trabalha no campo (MORIGI 2003: 24).

Apoiado especialmente nos trabalhos de Paulo Freire, a metodologia pedagógica dos trabalhos de educação do campo nos cursos do PRONERA desenvolve-se a partir dos temas geradores, que consiste em construir uma educação libertadora, em que o diálogo entre educandos e educadores é fundamental para a construção e o desenvolvimento das aulas.

Nos últimos anos têm ocorrido avanços, pois o programa hoje conta com legislação própria e é reconhecido pelo Decreto da Educação do Campo e do PRONERA (Decreto n. ${ }^{\circ}$ 7.352/2010) como integrante da Política Nacional de Educação do Campo. Ressaltamos ainda o fato de o PRONERA ter sido referência para a elaboração do Procampo - Licenciatura em Educação do Campo -, do Ministério da Educação, e para a criação do Pronacampo ${ }^{5}$. No entanto, acreditamos que há espaço e necessidade para muitos avanços, como a desburocratização dos recursos, a maior duração dos cursos, sobretudo os de EJA, e uma maior integração entre INCRA, universidades e movimentos sociais, entre outras questões.

Neste sentido, buscaremos a partir das experiências do programa com a Educação de Jovens e Adultos nos assentamentos e acampamentos rurais do estado do Rio de Janeiro fomentar o debate em torno desse projeto e da educação do campo.

\section{2- AS EXPERIÊNCIAS DO PROGRAMA NACIONAL DE EDUCAÇÃO NA REFORMA AGRÁRIA NO ESTADO DO RIO DE JANEIRO}

As discussões sobre o PRONERA no estado do Rio de Janeiro surgiram com a própria constituição do programa em nível nacional, assim como a consolidação do MST no estado no fim dos anos 1990.

A conjuntura do estado do Rio de Janeiro é marcada por um grande processo de urbanização e expropriação dos trabalhadores do campo, o que favorece a especulação imobiliária, principalmente na atualidade com a vinda dos grandes eventos para o estado. 
Diante desse quadro, podemos encontrar uma grande concentração fundiária demarcada pelo poder de um latifúndio atrasado, mas que tem o apoio do agronegócio e que tem trazido consequências tanto para o meio ambiente - o desmatamento, a perda da biodiversidade e contaminação dos solos - como também problemas sociais - grande exploração dos trabalhadores, gerando em algumas regiões condições análogas à escravidão, êxodo rural que resulta na concentração de excluídos nos centros urbanos, a violência e as condições de miserabilidade da população que resiste no campo e também das populações que ocupam as periferias. É nesse cenário de luta contra o latifúndio e do avanço desenfreado da urbanização que os movimentos sociais pautam a importância da Reforma Agrária no estado, em busca de garantias para o acesso e permanência na terra.

Dentro deste contexto, a luta pela educação também se apresenta essencial para a melhoria das condições de vida dos sujeitos do campo. Entende-se que a Educação do Campo não se dissocia da luta pela Reforma Agrária e são os movimentos sociais do campo que começam as discussões sobre a implementação do PRONERA. Lembremos que, no estado do Rio de Janeiro, os movimentos sociais que têm realizado com regularidade um debate sobre a Educação do Campo são o MST e a Federação dos Trabalhadores na Agricultura (FETAG) com o apoio da Comissão Pastoral da Terra (CPT).

As discussões no início seguiram o que estava sendo discutido em nível nacional, que é a problemática do analfabetismo nas áreas de assentamentos e acampamentos da Reforma Agrária. No estado, essa questão também é emblemática e por isso foi a principal ação do PRONERA por muitos anos.

Influenciados pelo protagonismo do MST na discussão sobre a educação do campo, os projetos da EJA realizados pelo PRONERAIRJ tiveram a preocupação de propiciar junto desta alfabetização uma formação política que contribuísse para que os sujeitos do campo se percebessem no processo de luta e identificassem seu assentamento ou acampamento como espaço de sociabilidade, de vida e de produção e reprodução das suas condições materiais. Nesse sentido, os projetos construídos deveriam ter como proposta política pedagógica o acúmulo histórico das práticas e teorias educacionais dos movimentos sociais.

O protagonismo dos movimentos sociais camponeses no batismo originário da Educação do Campo nos ajuda a puxar o fio de alguns nexos estruturantes desta "experiência" e, portanto, nos ajuda na compreensão do que essencialmente ela é e na "consciência de mudança" que assinala e projeta para além dela mesma. (CALDART 2012:259)

Entendendo a importância do programa para a educação nas áreas de Reforma Agrária, as universidades foram estimuladas a escrever projetos voltados à alfabetização de Jovens e Adultos - EJA, em parceria com os movimentos sociais.

Nesse sentido, no artigo ora apresentado dedicamos maior atenção aos cursos de EJA do PRONERA realizados no estado, pois é o segmento com maior número de cursos realizados. Tal fato nos proporciona apresentar de forma mais significativa os aspectos relevantes do desenvolvimento do programa, as principais dificuldades e, sobretudo, os desafios a serem superados na EJA nos assentamentos e acampamentos rurais do estado do Rio de Janeiro.

Sendo assim, o primeiro curso do PRONERA que aconteceu foi entre os anos 1999 e 2000, através da Universidade Federal Fluminense - UFF, que teve como título "Alfabetização de Trabalhadores Rurais em Assentamentos e Acampamentos nos Municípios do Estado". Este 
$\overline{\text { projeto foi realizado em áreas de assentamentos e acampamentos do MST e da FETAG. De }}$ acordo com a "Cartilha Nossa Terra, Nossas Vidas: um encontro na História" (2000), produzida a partir da experiência e interatividade (Andrade \& Di Pietro 2005) entre educadores e a equipe de coordenação, o projeto possibilitou a alfabetização em assentamentos e acampamentos distribuídos por diferentes regiões do estado, cursos de capacitação para os educadores e o incentivo à continuação dos estudos por parte dos educandosleducadores.

Logo após, aconteceu, em parceria entre Universidade Federal Rural do Rio de Janeiro - UFRRJ, o MST e FETAG, o projeto "Educação de Jovens e Adultos em Assentamentos de Reforma Agrária", nos anos 2001 e 2002; e em 2003 e 2004 o projeto "Ações Integradas para Educação de Jovens e Adultos nos Assentamentos de Reforma Agrária no Estado do Rio de Janeiro", somente com o MST.

De acordo com o projeto $^{6}$ e a dissertação de mestrado de Valdemir Lúcio Durigon, defendida junto ao curso de pós graduação em Educação Agrícola do Instituto de Agronomia da UFRRJ, os projetos tiveram como objetivo: garantir o processo de construção coletiva que vise ao resgate da cidadania através da inclusão escolar; proporcionar a valorização da vida através de práticas que viabilizem a aquisição de conhecimentos; possibilitar a discussão de um novo modelo de desenvolvimento do meio rural; garantir o acesso a conhecimentos críticos que contribuam para a permanência dos(as) trabalhadores(as) rurais no campo, sobretudo a sua juventude, através da saúde, lazer, trabalho agrícola de qualidade, identidade cultural, valorização dos gêneros e preservação ambiental, além de buscar integrar os grupos sociais, através de suas representações, às instituições de ensino e de política de desenvolvimento rural.

Em 2006 e 2007, ocorreu o projeto "EJA - Alfabetização e Escolarização de $1^{\circ}$ a $4^{\circ}$ Série", organizado pela Universidade do Estado do Rio de Janeiro - UERJ em parceria com o MST.

De acordo com Alentejano (2011), o trabalho envolveu inicialmente 480 alunos, divididos em 24 turmas de 20 alunos, localizados em 22 assentamentos e acampamentos rurais, distribuídos em 12 municípios espalhados pelas regiões da Baía da Ilha Grande, Médio Paraíba, Metropolitana, Baixadas Litorâneas, Norte e Noroeste Fluminense.

O projeto envolveu 24 educadores moradores dos assentamentos e acampamentos, 4 coordenadores locais vinculados ao MST, 4 graduandos da UERJ (bolsistas) responsáveis pelo acompanhamento político-pedagógico das turmas, 1 bolsista de apoio técnico e 1 Coordenador Geral.

O projeto desenvolveu-se dentro dos marcos da concepção da Educação do Campo e foi pautado pela forte interatividade entre universidade e movimento social, pois, segundo Alentejano (2011):

Tanto os encaminhamentos administrativos como os pedagógicos eram discutidos e deliberados no âmbito das reuniões da Coordenação, composta pelos 4 coordenadores locais vinculados ao MST, os 4 bolsistas-UERJ responsáveis pelo acompanhamento políticopedagógico das turmas, a bolsista apoio técnico e o Coordenador Geral. Foi também com base nessa metodologia de trabalho que as oficinas de capacitação dos educadores foram construídas coletivamente, inclusive com a participação dos educadores das turmas no planejamento e coordenação de atividades (Alentejano 2011).

Dentre os objetivos centrais expostos no projeto base do PRONERA MST/UERJ destaca-se o fortalecimento da educação nas áreas de reforma agrária, em consonância com os 
$\overline{\text { debates realizados no âmbito da Articulação Nacional por uma Educação do Campo. A ênfase }}$ maior foi: na valorização do saber e da cultura popular, dos valores humanistas, das práticas solidárias e do cuidado com o meio ambiente; a contribuição para a construção de uma Política Pública de Educação do Campo; a capacitação de educadores de jovens e adultos para atuação no processo de elevação da escolaridade dos educandos; a elevação da escolaridade e o incentivo ao retorno ao ensino formal das pessoas que vivem em assentamentos e acampamentos rurais no estado do Rio de Janeiro (Alentejano 2011).

Houve ainda outro projeto de EJA realizado com a UFRRJ em parceria com o MST e a FETAG; no entanto, esse projeto não foi concluído. Atualmente existem alguns cursos em andamento e outros concluídos recentemente no estado, tais como: Licenciatura em Educação do Campo pela UFRRJ em parceria com diversos movimentos; Graduação em Serviço Social pela UFRJ em parceria com o MST; Especialização em Trabalho, Educação e Movimentos Sociais pela Escola Politécnica de Saúde Joaquim Venâncio - EPSJV da Fundação Oswaldo Cruz - FIOCRUZ em parceria com o MST.

A partir da experiência dos autores deste artigo no acompanhamento de alguns desses projetos de EJA do PRONERA, somada aos diálogos com os coordenadores dos projetos citados, à análise de materiais e aos relatos produzidos nos quatro cursos concluídos e tudo isso associado à leitura analítica de referências teóricas e metodológicas sobre a educação do campo e o programa, buscaremos no próximo tópico sistematizar os principais avanços e desafios da PRONERAIEJA no estado do Rio de Janeiro.

\section{1 - AVANÇOS E DESAFIOS DO PRONERAIEJA NO ESTADO DO RIO DE JANEIRO}

Ao analisarmos o desenvolvimento do PRONERA no estado do Rio de Janeiro a partir dos cursos de EJA, iremos encontrar avanços em relação ao desenvolvimento da educação do campo, mas muitos desafios a serem superados. De acordo com Durigon (2005), ao analisar a experiência do PRONERAIEJA no assentamento Zumbi dos Palmares, situado no município de Campos dos Goytacazes, foi possível encontrar muitas similaridades em relação ao desenvolvimento da EJA pelo programa em diferentes estados brasileiros a partir das informações disponibilizadas pela primeira pesquisa nacional de educação na reforma agrária ${ }^{7}$.

Neste sentido, destacaremos aqui especialmente os avanços e desafios encontrados de forma similar nos quatros cursos analisados. Dentre os principais desafios podemos apontar:

\section{1- ATRASO NA LIBERAÇÃO DOS RECURSOS}

Nos quatros cursos analisados, houve relato de atraso na liberação dos recursos, fossem eles para iniciar o projeto quanto para o desenvolvimento dos mesmos. Segundo os coordenadores das pesquisas, especialmente o atraso no pagamento dos educadores e liberação recursos para as oficinas de capacitação acabam por desestimular os educandos e comprometer a mobilização nas áreas onde ocorriam os projetos. Em geral, os atrasos eram justificados pelo INCRA devido a incompatibilidades nas prestações de conta.

\section{2- A FALTA DE INFRAESTRUTURA E A LOGÍSTICA}

Os espaços cedidos para a realização das aulas do PRONERA nos assentamentos e acampamentos são na maioria das vezes muito precários. Essa precariedade é representada, 
sobretudo, pela falta de iluminação das salas de aula; cadeiras inadequadas, havendo situações em que os educandos tinham que sentar em cadeiras infantis; falta de merenda, quadro e material pedagógico básico, que por vezes chegavam às áreas com atraso em realização ao início das aulas.

No que se refere à logística, a distância entre o local das aulas e a casa dos assentados é reclamação recorrente, pois normalmente as aulas são realizadas durante a noite por conta do trabalho dos educandos, que acabam tendo que se deslocar em estradas de terra sem iluminação, situação agravada nos períodos de chuva, ou pelo fato de muitos educandos serem idosos ou em alguns casos terem problemas de visão.

\section{3- TEMPO DE DURAÇÃO DOS CURSOS}

A curta duração dos cursos do PRONERAIEJA realizados no estado do RJ é vista como um problema. O tempo perdido por conta dos atrasos nos recursos e paralizações dos projetos, associado ao fato de o período das aulas em determinados momentos coincidir com a época de maior trabalho na roça, o que leva a uma maior ausência dos educandos nas aulas, tem sido um entrave para o maior êxito do programa. No campo pedagógico, a curta duração pode ampliar a possibilidade de, ao invés de alfabetizar, transformar os educandos em analfabetos funcionais. Neste sentido, tem sido cada vez maior por parte dos movimentos sociais, dos coordenadores dos projetos e de daqueles que pesquisam o PRONERA a luta pela ampliação do tempo de duração dos projetos de EJA.

\section{4- RESISTÊNCIA À PROPOSTA TEÓRICA E METODOLÓGICA DO PRONERA E DA EDUCAÇÃO NO CAMPO}

Como relatamos anteriormente, os cursos de EJA do PRONERA trabalham em consonância com uma proposta de educação do campo emancipatória, tendo nos trabalhos de Paulo Freire a sua base, posteriormente tendo avançado a partir das contribuições teóricas e metodológicas de outros pesquisadores e, sobretudo, das experiências nos assentamentos e acampamentos rurais.

Tanto na educação das escolas formais urbanas quanto rurais ainda há um predomínio de uma pedagógica tradicional, na qual o professor é o dono do saber e o conhecimento prévio dos alunos é normalmente desconsiderado.

A resistência à proposta de trabalho a partir dos temas geradores, a uma educação que visa à emancipação e à transformação da realidade, tem se manifestado tanto dos educadores quanto de alguns educandos, pois na grande maioria das vezes essas pessoas tiveram uma educação tradicional.

Segundo Alentejano (2011)

O desafio da formação dos educadores populares compreende duas dimensões distintas, mas articuladas: a político-pedagógica e a técnica. Em termos político-pedagógicos o principal desafio está no desenvolvimento entre os educadores da perspectiva da autonomia, especialmente no âmbito de um Programa que trata da escolarização de trabalhadoras e trabalhadores rurais sem terra e que, portanto, precisa articular no processo educativo o debate sobre a realidade cotidiana e estrutural de exploração a que são submetidos. 
No que diz respeito à dimensão técnica, o problema está em superar a fragilidade da escolarização de boa parte dos educadores populares, o que faz com que muitos deles tenham profundas dificuldades na leitura, na escrita, no manuseio da linguagem e do raciocínio matemático, na compreensão da historicidade e da geograficidade dos processos sociais e naturais.

Outro agravante que torna esse desafio ainda maior é o problema da rotatividade dos educadores, uma vez que isto implica descontinuidade do trabalho e da própria formação dos educadores.

\section{5- A FALTA DE CERTIFICAÇÃO DOS EDUCANDOS}

Para os cursos de EJA realizados pelo PRONERA não houve uma certificação formal dos educandos que concluíram o curso por parte das Secretarias de Educação, sejam estadual ou municipais. Isso demonstra a necessidade e a importância de uma maior articulação entre os governos municipais, estadual e federal para viabilizar em todas as instâncias uma educação do campo que valorize o meio rural e seus sujeitos em todas as dimensões.

\section{2- OS PRINCIPAIS AVANÇOS DA PRONERA/EJA E DA EDUCAÇÃO DO CAMPO NO RIO DE JANEIRO}

Buscaremos agora, ainda que de forma sucinta, apontar os principais avanços conseguidos a partir dos cursos do PRONERAIEJA realizados no estado do Rio de Janeiro.

\section{1- GESTÃO PARTICIPATIVA ENTRE MOVIMENTOS SOCIAIS E UNIVERSIDADE}

Em geral, os projetos de EJA do PRONERA no estado do Rio de Janeiro tiveram uma gestão compartilhada entre os movimentos sociais e as universidades. A dinâmica da construção coletiva da gestão compartilhada, em geral, envolveu as diversas instâncias organizacionais do projeto, tais como a construção das oficinas de capacitação, construção de material didático, escolha de material didático-pedagógico e outros. Parte desse aspecto positivo deve-se à parceria já existente anteriormente entre alguns segmentos das universidades e os movimentos sociais demandantes. No entanto, é importante mencionar que em todos os casos houve problemas na relação entre as fundações que administram os recursos e os gestores do projeto (movimentos sociais e professoreslestagiários das universidades).

\section{2- A FORMAÇÃO DOS EDUCADORES}

Apesar da resistência de alguns educadores e educandos em relação ao trabalho com os temas geradores, a escolha de assentadoslacampados para ministrar as aulas, a realização de cursos de capacitação para os educadores e a utilização de metodologias específicas de trabalho que consideravam as características dos assentamentoslacampamentos, dos educadores e dos 
educandos sem dúvida fez avançar a proposta de educação do campo no estado do Rio de Janeiro e diminuir a resistência a essa proposta emancipatória de educação.

\section{3- O PROTAGONISMO DO MST}

Assim como em nível nacional (Araújo 2004), há uma predominância do MST como demandante dos cursos do PRONERA no estado do Rio de Janeiro. Temos que destacar o protagonismo do MST, considerando que esse movimento social participou da realização de todos os cursos do programa no estado. Tal fato é fruto da maior organização do MST frente aos outros movimentos sociais rurais no Rio de Janeiro, assim como, reflexo da importância que o MST dá à questão da educação do campo dentro do seu projeto de reforma agrária.

\section{4- A VALORIZAÇÃO DO PROCESSO DE ESCOLARIZAÇÃo}

Apesar de vários educandos abandonarem por diversos motivos os cursos do PRONERAIEJA, aqueles que conseguem concluir o curso demonstram imensa vontade de prosseguir seu processo de escolarização, pois para esses trabalhadores rurais o curso de alfabetizaçãolescolarização de Jovens e Adultos foi muito importante para melhorar sua autoestima, a segurança no seu trabalho, a relação com outras pessoas em diferentes espaços sociais e também para auxiliar nas atividades escolares de seus filhos. Esse fato demonstra, por um lado, a necessidade de rediscutir a temporalidade dos cursos do programa, assim como a continuidade dos cursos em todos os níveis de ensino.

Ainda que de forma sucinta e genérica, os desafios e avanços do PRONERA/EJA apontados acima demonstram bem como essa política pública tem sido importante para o campesinato fluminense. No entanto, é fundamental impulsionar a discussão sobre o papel e a repercussão que o programa pode ter nos próximos anos dentro de um novo projeto de desenvolvimento rural.

\section{CONSIDERAÇÕES FINAIS}

Após a descrição dos projetos realizados, consideramos importante para fomentar o debate em torno do PRONERA e da Educação do Campo a realização de um balanço da contribuição destes projetos de alfabetização e escolarização para a formação dos trabalhadores do campo, tanto na dimensão da formação humana quanto na dimensão da formação política. Por isso, abaixo seguem algumas considerações.

O PRONERA completou em 2013 seus 15 anos de existência. Dessa forma, consideramos fundamental que o programa tenha continuidade como parte da luta pelo fortalecimento de um processo de construção de um novo rural, no qual os seus sujeitos sejam respeitados e sua história possa ser contada, entendendo que a educação é o meio pelo qual o ser humano busca a sua emancipação. Este programa, como dito anteriormente, é uma conquista da luta dos movimentos sociais do campo e, portanto, apesar de ter se tornado uma política pública, não pode perder de vista o protagonismo dos movimentos sociais, principalmente a sua perspectiva de luta.

A realidade dos assentamentos e acampamentos da Reforma Agrária ainda é muito alarmante, sobretudo a questão do analfabetismo. Nesse sentido, é necessário pensar em novas metodologias de trabalho com a EJA que deem conta de superar essa dívida histórica com os trabalhadores do campo. 
A realização dos cursos do PRONERAlEJA nas áreas de assentamentos e acampamentos de Reforma Agrária proporcionou a alfabetização juntamente com o debate da Educação do Campo para muitos jovens e adultos.

A Educação do Campo abrange um debate que deve ter como perspectiva a formação dos sujeitos, que vai desde a alfabetização até ao acesso ao ensino superior para crianças, jovens e adultos. Sendo assim, este debate precisa ser apropriado por todos os trabalhadores, sejam dos acampamentos e dos assentamentos como de todos que lutam pela Reforma Agrária. É preciso entender que a educação é um direito da classe trabalhadora e é um dever do estado propiciar os recursos e estruturas necessárias para que seja garantida uma educação que interesse aos sujeitos do campo, como nos alerta Caldart (2012: 263):

Constitui-se como luta social pelo acesso dos trabalhadores do campo à educação (e não a qualquer educação) feita por eles mesmos e não apenas em seu nome. A Educação do Campo não é para nem apenas com, mas sim, dos camponeses, expressão legítima de uma pedagogia do oprimido.

Os cursos de EJA deram a oportunidade de os educandos participarem de seminários e encontros sobre a Educação do Campo, assim como de refletirem sobre as práticas pedagógicas e levarem este debate para suas comunidades.

Embora o formato do programa, em especial para a Educação de Jovens e Adultos, muitas vezes não garanta total eficiência no que tange à alfabetização, ele contribui para ajudar na construção de uma educação mais emancipadora. Ainda assim é preciso fazer a luta por políticas públicas que garantam o direito a uma educação pública e de qualidade.

Percebe-se a dificuldade de permanência nas turmas e conclusão destas, seja por questões estruturais, como transporte, infraestrutura das salas e material pedagógico, seja por questões de falta de estímulo e das próprias condições de vida em que estes sujeitos se encontram, como trabalho exaustivo e as limitações físicas. Isso nos leva a concluir que, mesmo que o programa tenha contribuído, ele não é o suficiente para sanar o grande problema que ainda podemos encontrar nas áreas rurais, o alto índice de analfabetismo.

Com isso, defendemos que no estado do Rio de Janeiro é preciso continuar avançando nas parcerias com as universidades, para que os movimentos sociais bem como a classe trabalhadora tenham de fato acesso ao conhecimento científico produzido na academia e que este conhecimento venha interagir com o conhecimento popular. Neste sentido, acreditamos que o PRONERA deva estar sendo rediscutido para continuar avançando e contribuindo para tornar os trabalhadores do campo sujeitos de sua própria História.

\section{NOTAS}

${ }^{1}$ Licenciada em Educação do Campo em , na área de Línguas, Arte e Literatura pelo PRONERA em parceria com a UFMG. Possui Pós-Graduação (especialização) pelo PRONERA em Trabalho, Educação e Movimentos Sociais em parceria com a EPSJV/FIOCRUZ e o MST. Participou da coordenação do PRONERA convênio INCRAIUERJ\MST (2006-2007). É do Setor de Educação do MST\RJ 
${ }^{2}$ Licenciada em Ciências Agrícolas pela UFRRJ. Possui Pós-Graduação (especialização) pelo PRONERA em Trabalho, Educação e Movimentos Sociais em parceria com a EPSJV/FIOCRUZ e o MST. É do Setor de Educação do MSTIRJ.

3 Professor de Geografia. Mestre em Desenvolvimento, Sociedade e Agricultura pela UFRRJ/CPDA e Doutorando em Geografia pelo PPGEO/UFF. Participou da coordenação do PRONERA convênio INCRAIUERJMMST (2006-2007).

${ }^{4}$ Censo IBGE 2010.

${ }^{5}$ O Programa Nacional de Educação do Campo (Pronacampo) é uma ação do Governo Federal resultado da mobilização dos movimentos sociais e sindicais do campo, para construção de referências de política nacional de educação do campo, com apoio do MEC. O Pronacampo oferece apoio técnico e suporte financeiro para estados e municípios implementarem suas respectivas políticas de Educação do Campo, através de um conjunto de ações articuladas, que atendem às escolas do campo e quilombolas em quatro eixos: gestão e práticas pedagógicas, formação de professores, educação de jovens e adultos e educação profissional e tecnológica e infraestrutura. O programa trabalha a educação contextualizada, ou seja, promovendo a interação entre conhecimento científico e os saberes das comunidades.

${ }^{6}$ Disponível como anexo na dissertação de mestrado de Valdemir Lúcio Durigon intitulada "Concepção e Prática de Projetos Educacionais em Assentamentos Rurais no Estado do Rio de Janeiro: o PRONERA no Zumbi dos Palmares em Campos dos Goytacazes" - defendida no ano de 2005 junto ao Programa de Pós Graduação em Educação Agrícola na UFRRJ.

${ }^{7}$ Disponível no site do INEP (www.inep.gov.br).

\section{REFERÊNCIAS BIBLIOGRÁFICAS}

ALENTEJANO. Paulo Roberto Raposo. "Os desafios da educação de jovens e adultos em assentamentos e acampamentos rurais no estado do Rio de Janeiro". In: ALVARENGA, Marcia (org.). Educação de Jovens e Adultos em tempos e contextos de aprendizagens. 1 edição. Rio de Janeiro; Rovelle, 2011, v.1, p. 45-62.

ANDRADE, Marcia Regina \& DI PIERRO, Maria Clara. Relatório Geral de Avaliação Externa do Programa. São Paulo-SP, 2004.

ARAÚJO, Severina Garcia. "O Pronera e os movimentos sociais: protagonismo do MST". In: ANDRADE, Marcia Regina, DI PIERRO, Maria Clara, MOLINA, Mônica Castagna \& JESUS, Sônia Meire Santos Azevedo de (orgs.). A educação na reforma agrária em perspectiva: uma avaliação do Pronera. São Paulo: Ação Educativa; Brasília: PRONERA, 2004. 
ARROYO, Miguel. "Por um tratamento público da Educação do Campo". In: MOLINA, Mônica Castagna \& JESUS, Sonia Meire Santos Azevedo. (orgs.) Por Uma Educação do Campo 5. Brasília: Articulação Nacional por uma Educação do Campo, 2004.

BRASIL. Decreto 7.325/2010. Brasília, 2010. Disponível em: http://www.planalto.gov.br/ccivil_03/_ato2007-2010/2010/decreto/d7352.htm. Acessado em: 13/04/2013.

CALDART, Roseli Salete. Educação do Campo. CALDART, Roseli Salete. PEREIRA, Isabel Brasil. ALENTEJANO, Paulo. FROGOTTO, Gaudêncio. (orgs.) Dicionário da Educação do Campo. Rio de Janeiro, São Paulo: Escola Politécnica Joaquim Venâncio, Expressão Popular, 2012. p. 257-265.

CAMPOS, Samuel Pereira. "Projetos de Educação de Jovens e Adultos: concepções, problemas e resultados de práticas educativas". In: ANDRADE, Marcia Regina, DI PIERRO, Maria Clara, MOLINA, Mônica Castagna \& JESUS, Sônia Meire Santos Azevedo de (orgs.). A educação na reforma agrária em perspectiva: uma avaliação do Pronera. São Paulo: Ação Educativa; Brasília: PRONERA, 2004.

CNBB, MST, UNICEF, UNESCO e UnB. Conferência Nacional: Por uma Educação Básica do Campo. CTE - Centro de Treinamento Educacional de Luziânia-GO, Julho de 1998.

DURIGON, Valdemir Lúcio. Concepção e prática de projetos educacionais em Assentamentos Rurais no estado do Rio de Janeiro: o PRONERA no Zumbi dos Palmares em Campos dos Goytacazes. Dissertação (Mestrado em Educação Agrícola). Programa de Pós-Graduação em Educação Agrícola: Instituto de Agronomia Universidade Federal Rural do Rio de Janeiro. Seropédica, 2005.

INEPIMEC. Panorama da Educação no Campo. Brasília - DF, 2007. Disponível em www.inep.gov.br. Acesso em 15 de Maio de 2013.

I Pesquisa Nacional da Educação na Reforma Agrária (PNERA). Disponível em: www.inep.gov.br. Acesso em 05/05/2013.

MDAIINCRA. Manual de Operações do Programa Nacional de Educação na Reforma Agrária (PRONERA). Edição Revista e Atualizada. Brasília - DF, 2004.

MORIGI, Valter. Escola do MST uma utopia em construção. Porto Alegre - RS, Editora Mediação, 2003.

KOLLING, Edgar J., NÉRY, Irmão \& MOLINA, Mônica C. (orgs.). Por uma educação básica do campo. Brasília: UnB, 1999.

SANTOS, Clarice Aparecida dos. Balanço Político e Linhas de Ação do PRONERA Rumo aos 10 Anos. Por uma Educação do Campo. Campo-Politicas-Publicas-Educação. Brasília: INCRA; MDA, 2008. 109p. (NEAD Especial, 10) 
.Programa Nacional de Educação na Reforma Agrária (PRONERA). In: CALDART, Roseli Salete. PEREIRA, Isabel Brasil. ALENTEJANO, Paulo. FROGOTTO, Gaudêncio. (orgs.) Dicionário da Educação do Campo. Rio de Janeiro, São Paulo: Escola Politécnica Joaquim Venâncio, Expressão Popular, 2012. p. 629-638.

UFFIFETAGIMST. Cartilha Nossa Terra, Nossas Vidas: um encontro na História. Edição FASEICECIPIFUNDO NOVIB. Rio de Janeiro, 2000.

UFRRJFETAGIMST. Projeto de Educação de Jovens e Adultos em Assentamentos de Reforma Agrária. Seropédica, 2000. 